\title{
Prehypertension and Hypertension among Schoolchildren in Brazzaville, Congo
}

\author{
Bertrand Fikahem Ellenga Mbolla, ${ }^{1,2}$ Annie Rachel Okoko,, \\ Jean Robert Mabiala Babela, ${ }^{2,3}$ Gaston Ekouya Bowassa, ${ }^{2,3}$ Thierry Raoul Gombet, ${ }^{1,2}$ \\ Suzy-Gisèle Kimbally-Kaky, ${ }^{1,2}$ and Benjamin Longo-Mbenza ${ }^{4}$ \\ ${ }^{1}$ Department of Cardiology, University Hospital of Brazzaville, BP 32, Brazzaville, Congo \\ ${ }^{2}$ Department of Medecine, Faculty of Health Science, Marien Ngouabi University, BP 2672, Brazzaville, Congo \\ ${ }^{3}$ Department of Pediatrics, University Hospital of Brazzaville, BP 32, Brazzaville, Congo \\ ${ }^{4}$ Faculty of Health Science, Walter Sisulu University, Mthatha, P.O. Box 5117, Eastern Cape, South Africa \\ Correspondence should be addressed to Bertrand Fikahem Ellenga Mbolla; ellenga_bertrand@hotmail.com
}

Received 13 April 2014; Accepted 6 May 2014; Published 20 May 2014

Academic Editor: B. Waeber

Copyright (C) 2014 Bertrand Fikahem Ellenga Mbolla et al. This is an open access article distributed under the Creative Commons Attribution License, which permits unrestricted use, distribution, and reproduction in any medium, provided the original work is properly cited.

\begin{abstract}
Background. To determine the prevalence and associated factors of prehypertension (pre-HT) and hypertension (HT) in schoolchildren at Brazzaville (Congo). Methods. This cross-sectional study was conducted from March to May 2011 in five representative urban schools in Brazzaville. American Pediatric Society's definition of pre-HT and HT was used. The measurement of blood pressure was obtained using auscultator method. Univariable and multivariable analyses were performed to establish associations between blood pressure levels and sociobiographical factors. Results. 603 children were included. The mean age was $11.8 \pm 3.6$ years (range $5-18$ years). The prevalence of pre-HT was $20.7 \%(n=125)$. Factors associated with pre-HT were secondary school $(P=0.02)$, private schools $(P<0.004)$, migrants $(P=0.03)$, the obese $(P=0.004)$, high socioeconomic level $(P<0.01)$, and overweight $(P=0.02)$. In logistic regression, the independent determinants of pre-HT were secondary school $(P=0.0001)$, migration $(P=0.04)$, obesity $(P=0.004)$, and overweight $(P=0.01)$. The prevalence of HT was $10.1 \%(n=61)$ during the first screening and 3.3\% $(n=20)$ in second screening. The independent determinants of HT were obesity $(P=0.0001)$ and overweight $(P=0.0001)$. Conclusion. Pre-HT and HT are emerging as a mass problem in Congolese schoolchildren with urban migration and overweight/obesity to be controlled and prevented.
\end{abstract}

\section{Introduction}

Hypertension (HT) in children is a rare concern whereas HT in adults is a global public health problem, according to World Health Organization (WHO) [1]. The prevalence of $\mathrm{HT}$ is reported in 4 to $15 \%$ children worldwide [2], with increasing trends during recent decades [3,4]. This increase is attributable to particular stress of mega cities in industrialized countries and lifestyle and diet whose impact on body size is well established. In sub-Saharan Africa (SSA) which is facing epidemiological transition, the prevalence of HT in child varies by regions: $4.9 \%$ in schools from Sudan [5] and 29.4\% from South Africa [6]. However, no data on HT and prehypertension (pre-HT) is available in schoolchildren from Republic of Congo.

The objectives of this study were to determine the prevalence of pre-HT and HT and to identify its contributing factors, which would establish an effective prevention program starting from a young age in Brazzaville, Congo.

\section{Methods}

2.1. Type, Period, and Materials. This cross-sectional study was conducted from March to May 2011 in five schools of Brazzaville, divided in two public schools and three private schools. These institutions were selected by cluster sampling 
TABLE 1: Epidemiological characteristics of the children studied.

\begin{tabular}{|c|c|c|c|c|}
\hline & All $(n=603)$ & Girls $(n=325)$ & Boys $(n=278)$ & $P$ value \\
\hline Adolescents & $308(51)$ & $192(59)$ & $116(41.7)$ & $<0.05$ \\
\hline Migration & $67(11)$ & $40(12.3)$ & $27(9.7)$ & NS \\
\hline Number of siblings & $4 \pm 1.8$ & $4 \pm 1.8$ & $3.9 \pm 1.9$ & NS \\
\hline Promiscuity & $275(45.6)$ & $150(46.2)$ & $125(45)$ & NS \\
\hline Primary school & $315(52.2)$ & $155(47.7)$ & $160(57.6)$ & NS \\
\hline Secondary school & $288(47.8)$ & $170(52.3)$ & $118(42.4)$ & NS \\
\hline Private school & $319(53)$ & $175(53.8)$ & $144(51.8)$ & NS \\
\hline Public school & $284(47)$ & $150(46.2)$ & $134(48.2)$ & NS \\
\hline $\mathrm{HSL}^{*}$ & $360(60)$ & $196(60.7)$ & $164(59)$ & NS \\
\hline Orphans & $38(6.3)$ & $25(7.7)$ & $13(4.7)$ & NS \\
\hline
\end{tabular}

Data are mean \pm standard deviation or number (\%).

*HSL: high socioeconomic level.

(cluster was defined as all establishments of a school district), after a random selection of $1 / 10$ was carried out among 219 schools from the city of Brazzaville at the time of the survey. At the time of the study, this town had three school districts, according to the division made by the Department of Elementary and Secondary Education of Congo. The criteria of inclusion approach were consistent with that of Kimbally-kaky et al. [7]. Thus, the calculated sample size was $600+6(10 \%$ potential missing $)=606$ eligible schoolchildren .

The parents, schoolchildren, and schools responsible authorities were sensitized about the aim, the significance, and the timetable for the study. Ethical issues were taken into account according to the Helsinki Declaration. The learners were interviewed and examined by investigators after prior training. Systolic blood pressure (SBP) and diastolic blood pressure (DBP) were recorded three times according to the American Pediatrics Society recommendations, using auscultatory method [8] by aneroïde sphygmomanometer (Spengler, France). The average of three taken pressures was retained.

2.2. Variables. The analyzed variables were age (years), sex, weight $(\mathrm{kg})$, height $(\mathrm{cm})$, and body mass index (BMI) in $\mathrm{kg} / \mathrm{m}^{2}$, malnutrition, overweight, obesity, adolescence, migration, number of siblings, promiscuity, school sector activity (primary, secondary, public, and private), high socioeconomic level, SBP in $\mathrm{mm} \mathrm{Hg}$, DBP in $\mathrm{mm} \mathrm{Hg}$, pulse pressure (PP) in $\mathrm{mm} \mathrm{Hg}, \mathrm{HT}$, and pre-HT.

2.3. Definitions. Adolescence was defined by WHO. Migration is defined by expatriation in Brazzaville since three years. Promiscuity was considered the presence of at least three children in the bedroom. The high socioeconomic level was defined according to parental occupation, namely, civil servants, traders, or a higher income than twice the minimum salary in Congo. Malnutrition was defined for $\mathrm{BMI}<5$ th percentile of WHO reference, overweight for BMI between 85 th and 95th percentile, and obesity for BMI $>95$ th percentile [9]. Pre-HT was defined for SBP and DBP between 85th and 95th percentile of American Pediatrics Association curves reference [10]. HT was defined by SBP and DBP $\geq$
TABLE 2: Clinical characteristics of the subjects studied.

\begin{tabular}{lcccc}
\hline & All & Girls & Boys & $P$ value \\
\hline Weight $(\mathrm{Kg})$ & $39.2 \pm 14.8$ & $40.5 \pm 14$ & $37.7 \pm 15.5$ & 0.01 \\
Height $(\mathrm{cm})$ & $145 \pm 18.8$ & $146.1 \pm 16$ & $144 \pm 20.7$ & NS$^{*}$ \\
BMI $\left(\mathrm{kg} / \mathrm{m}^{2}\right)^{\dagger}$ & $17.8 \pm 3.2$ & $18.3 \pm 3.3$ & $17.2 \pm 2.3$ & 0.001 \\
SBP $(\mathrm{mm} \mathrm{Hg})^{\ddagger}$ & $112.8 \pm 13$ & $114.5 \pm 12.7$ & $110.7 \pm 13$ & 0.001 \\
DBP $(\mathrm{mm} \mathrm{Hg})^{\S}$ & $73.6 \pm 8.8$ & $74.5 \pm 9$ & $72.7 \pm 8.6$ & NS \\
PP $(\mathrm{mm} \mathrm{Hg})^{\#}$ & $39 \pm 9$ & $40.2 \pm 8.6$ & $38 \pm 9.2$ & NS \\
\hline
\end{tabular}

Data are mean \pm standard deviation.

${ }^{*} \mathrm{NS}$ : not significant $(P>0.05),{ }^{\dagger} \mathrm{BMI}$ : body mass index; ${ }^{*} \mathrm{SBP}$ : systolic blood pressure, ${ }^{\complement} \mathrm{DBP}$ : diastolic blood pressure; ${ }^{\#} \mathrm{PP}$ : pulse pressure.

95th percentile of American Pediatrics Association curves reference [10].

2.4. Statistical Analysis. Data were expressed as proportions for categorical variables and as mean \pm standard deviation for continuous variables. In univariate analysis, Student $t$ test, chi-square test, and odds ratio (OR) with 95\% confidence interval (CI) were used for comparisons of means and proportions and associations, respectively. In multivariate analysis, after adjusting for confounding factors, logistic regression models identified independent determinants of pre-HT and HT. The criterion for statistical significance was $P$ value $<0.05$. All analyses were performed using SPSS software version 10.0 for Windows (SPSS Inc., Chicago, IL, USA).

\section{Results}

In total, 603 learners (response rate of 99.5\%) participated with 325 girls (54\%) and 278 boys (46\%) having similar $(P=0.08)$ age (mean $11.8 \pm 3.6$ years, range $5-18$ years $)$. Epidemiological characteristics were similar $(P>0.05)$ between girls and boys (Table 1 ).

Table 2 presents comparisons of mean levels of weight, height, BMI, SBP, DBP, and PP between girls and boys: similar $(P>0.05)$ levels of height, SBP, DBP, and PP between girls and boys, whereas girls were significantly $(P<0.05)$ heavier (Height and BMI) than boys. Malnutrition, overweight, and 
TABLE 3: Univariable odds of pre-HT.

\begin{tabular}{|c|c|c|c|c|c|}
\hline Variables & pre-HT & No pre-HT & OR & $95 \%$ CI & $P$ value \\
\hline Malnutrition & $10(8)$ & $52(10.9)$ & 0.71 & $0.33-1.4$ & 0.22 \\
\hline Primary school & $40(32)$ & $275(57.5)$ & 0.34 & $0.22-0.52$ & $<0.00001$ \\
\hline Private school & $83(66.4)$ & $236(49.4)$ & 2.02 & $1.34-3.07$ & 0.0004 \\
\hline Public school & $42(33.6)$ & $242(50.6)$ & 0.49 & $0.32-0.74$ & 0.0004 \\
\hline Secondary school & $85(68)$ & $203(42.5)$ & 2.87 & $1.89-4.39$ & $<0.000001$ \\
\hline Migration & $21(16.8)$ & $46(9.6)$ & 1.89 & $1.06-3.29$ & 0.02 \\
\hline Obesity & $11(8.8)$ & $14(2.9)$ & 3.19 & $1.37-7.27$ & 0.006 \\
\hline Orphan & $7(5.6)$ & $31(6.5)$ & 0.85 & $0.34-1.92$ & 0.45 \\
\hline Promiscuity & $47(37.6)$ & $228(47.7)$ & 0.66 & $0.43-0.98$ & 0.02 \\
\hline Adolescents & $84(67.2)$ & $224(46.9)$ & 2.31 & $1.53-3.53$ & $<0.0001$ \\
\hline $\mathrm{HSL}^{*}$ & $88(70.4)$ & $272(57.1)$ & 1.78 & $1.17-2.74$ & 0.004 \\
\hline Overweight & $16(12.8)$ & $31(6.5)$ & 2.11 & $1.09-3.98$ & 0.019 \\
\hline
\end{tabular}

${ }^{*}$ HSL: high socioeconomic level.

TABLE 4: Logistic regression to determine independent role of type of school, migration, obesity, HSL, and overweight on presence of pre-HT in schoolchildren.

\begin{tabular}{|c|c|c|c|c|c|}
\hline Independent variables & $\beta$ coefficient & Standard error & Wald $\chi^{2}$ & OR $(95 \%$ CI $)$ & $P$ value \\
\hline Private school (yes/no) & 0.376 & 0.305 & 1.232 & $1.456(0.8-2.65)$ & 0.217 \\
\hline Secondary school (yes/no) & 0.902 & 0.230 & 3.921 & $2.466(1.57-3.87)$ & 0.0001 \\
\hline Migration (yes/no) & 0.602 & 0.299 & 2.014 & $1.826(1.01-3.28)$ & 0.044 \\
\hline Obesity (yes/no) & 1.221 & 0.430 & 2.835 & $3.391(1.45-7.89)$ & 0.0046 \\
\hline HSL $^{*}$ (yes/no) & 0.084 & 0.306 & 0.276 & $1.088(0.59-1.98)$ & 0.782 \\
\hline Overweight (yes/no) & 0.859 & 0.341 & 2.517 & $2.361(1.2-4.61)$ & 0.011 \\
\hline
\end{tabular}

${ }^{*}$ HSL: high socioeconomic level.

obesity were reported in $62(10.2 \%), 47$ (7.8\%), and $25(4.1 \%)$ learners, respectively.

The prevalence of pre-HT was $20.7 \%$ out of all schoolchildren $(n=105), 24.3 \%$ in girls $(n=79)$, and $16.6 \%$ in boys $(n=$ $46)$. The mean age was $13 \pm 3.3$ years (range $5-18$ years) for pre-HT children, versus, $11.5 \pm 3.7$ years (range $5-18$ years) for children without pre-HT $(P<0.0001)$. The mean BMI in preHT children was $19.5 \pm 3.5 \mathrm{~kg} / \mathrm{m}^{2}$ (range 12.8 to $30.1 \mathrm{~kg} / \mathrm{m}^{2}$ ) versus, $17.3 \pm 3 \mathrm{~kg} / \mathrm{m}^{2}$ (range: 12.5 to $29.3 \mathrm{~kg} / \mathrm{m}^{2}$ ) for learners without pre-HT $(P<0.01)$. The univariate associated factors of pre-HT were the private school, secondary school, obesity, overweight, and high socioeconomic level (Table 3). In logistic regression, the independent determinants of preHT were secondary school $(P=0.0001)$, migration $(P=$ $0.04)$, obesity $(P=0.004)$, and overweight $(P=0.01)$ (Table 4).

The prevalence of HT in the first screening was $10.1 \%$ ( $n=61$ cases $)$ and $3.3 \%(n=20)$ in the second screening. There were 12 girls and 8 boys and the mean age of HT children was $12.8 \pm 2.6$ years versus $11.8 \pm 3.7$ years for children without HT $(P>0.05)$. The BMI of children who had HT was $20.3 \pm 4.4 \mathrm{~kg} / \mathrm{m}^{2}$ versus $17.7 \pm 3 \mathrm{~kg} / \mathrm{m} 2$ for children without HT $(P<0.001)$. Only overweight and obesity had a positive and significant univariate association with HT (Table 5). In logistic regression, the independent determinants of HT (Table 6$)$ were obesity $(P=0.0001)$ and overweight $(P=0.0001)$.

\section{Discussion}

This study reported the burden and contributing factors of pre-HT and HT in a sample of schoolchildren in Brazzaville, Congo. Rigorous sampling criteria of this study and that of other authors [10] demonstrated high rates of high blood pressure.

The prevalence of pre-HT was $20.7 \%$ associated with several factors in the present survey. These contributing factors included private school, secondary school, migrant children, children belonging to a family of high socioeconomic status, children with obesity and overweight, and adolescents. Prevalence of pre-HT varies by puberty, country, and social environment (degree of urbanization). Low prevalences of pre-HT are reported $4.9 \%$ by Salman et al. in Sudan in schools [5], 5.7\% by Abolfotouh et al. in Egypt for adolescents in schools [11], 7.6\% by Salvadori et al. in Canada [12], and 8.6\% by Kemp et al. in rural areas of South Africa [6]. Intermediate prevalences of pre-HT are observed $12.3 \%$ by Sharma et al. in schools of India [13] and $15 \%$ by Guo et al. in rural areas of China [14]. However, higher rates of pre-HT were reported by this study and estimated $20.7 \%$ and similar with $22.2 \%$ and $25 \%$ among Nigerian adolescents from rural and urban areas, respectively [15].

Agyemang et al. in Ghana found that the level of blood pressure increased with age, and this was more pronounced in urban areas [16]. These facts were also reported by Paradis 
TABLE 5: Univariable odds of HT.

\begin{tabular}{|c|c|c|c|c|c|}
\hline Variables & $\mathrm{HT}$ & No HT & OR & $95 \% \mathrm{CI}$ & $P$ value \\
\hline Malnutrition & $3(15)$ & $59(10.1)$ & 1.56 & $0.44-5.49$ & 0.24 \\
\hline Primary school & $10(50)$ & $305(52.4)$ & 0.90 & $0.37-2.21$ & 0.50 \\
\hline Private school & $11(55)$ & $307(52.7)$ & 1.09 & $0.44-2.68$ & 0.51 \\
\hline Public school & $9(45)$ & $275(47.3)$ & 0.91 & $0.36-2.27$ & 0.51 \\
\hline Secondary school & $10(50)$ & $277(47.6)$ & 1.10 & $0.45-2.68$ & 0.50 \\
\hline Migration & $3(15)$ & $64(11)$ & 1.42 & $0.32-4.62$ & 0.28 \\
\hline Obesity & $4(20)$ & $21(3.6)$ & 6.67 & $2.05-21.71$ & 0.004 \\
\hline Orphan & $1(5)$ & $37(6.4)$ & 0.77 & $0.10-5.95$ & 0.45 \\
\hline Promiscuity & $5(25)$ & $269(46.2)$ & 0.38 & $0.13-1.08$ & 0.047 \\
\hline Adolescents & $13(65)$ & $294(50.5)$ & 1.81 & $0.71-4.62$ & 0.147 \\
\hline $\mathrm{HSL}^{*}$ & $11(55)$ & $348(60)$ & 0.81 & $0.33-1.99$ & 0.409 \\
\hline Overweight & $6(30)$ & $41(7)$ & 5.65 & $2.06-15.49$ & 0.002 \\
\hline
\end{tabular}

${ }^{*}$ HSL: high socioeconomic level.

TABLE 6: Logistic regression to determine the independent role of type of school, obesity, orphans, adolescence, HSL, and overweight on presence of HT in schoolchildren.

\begin{tabular}{|c|c|c|c|c|c|}
\hline Independent variables & $\beta$ coefficient & Standard error & Wald $\chi^{2}$ & OR $(95 \% \mathrm{CI})$ & $P$ value \\
\hline Private school (yes/no) & 0.667 & 0.725 & 0.919 & $1.948(0.46-8.08)$ & 0.357 \\
\hline Secondary school (yes/no) & 0.561 & 0.657 & 0.853 & $1.752(0.48-6.36)$ & 0.393 \\
\hline Migration (yes/no) & 0.369 & 0.734 & 0.503 & $1.447(0.34-6.11)$ & 0.614 \\
\hline Obesity (yes/no) & 4.463 & 1.144 & 3.900 & $86.81(9.21-818)$ & 0.0001 \\
\hline Orphans (yes/no) & -0.719 & 0.976 & -0.737 & $0.486(0.07-3.3)$ & 0.461 \\
\hline Adolescents (yes/no) & 0.981 & 0.692 & 1.418 & $2.669(0.68-10)$ & 0.156 \\
\hline HSL $^{*}$ (yes/no) & -0.723 & 0.666 & -1.085 & $0.485(0.13-1.79)$ & 0.277 \\
\hline Overweight (yes/no) & 3.304 & 0.850 & 3.885 & $27.2(5.14-144)$ & 0.0001 \\
\hline
\end{tabular}

${ }^{*}$ HSL: high socioeconomic level.

et al. in USA, with a prevalence of $12 \%$ for children aged 9 years, $22 \%$ for children aged 13 years, and $30 \%$ for children aged 16 years ago [17]. As remote areas, however, aging was not associated with increasing blood pressure among these Congolese schoolchildren.

The most important determinants of pre-HT in this survey were migration, obesity, and overweight. The literature reports much higher prevalence of pre-HT children with overweight or obesity $[6,18,19]$. Moreover, after migration from rural areas toward town of Brazzaville, urbanization and westernization are driving both epidemiological transition and nutrition transition characterized by changes in lifestyle and dietary habits. Thus, physical inactivity, excessive intake of salt, refined sugar, and polysaturated fats increase the risk of overweight/obesity and cardiovascular risk among children $[20,21]$. But these factors are difficult to evaluate in our context. Other risk factors were found. These include children in secondary schools, private schools, and children with high socioeconomic level. Indeed, the majority of high school students are adolescents, in which a high prevalence of pre-HT is described by other authors [4, 15, 17, 22, 23]. In this study, the HT was found in $10 \%$ of children in Brazzaville, Congo. It is reported that repeated blood pressure measurements and screening may reduce prevalence of HT in some data from the literature [24], but not in the present study. The prevalence of HT varies by the country of residence and age [24]. The prevalence of HT is continuously increasing in developing countries as shown by Chiolero et al. in the Seychelles: $6.9 \%$ of children in 2004 and $7.8 \%$ in 2006 [3]. In Africa, low prevalences of HT were reported as $4.9 \%$ in Sudan [5] and 4\% in Egypt [11]. On the other hand, the rate of $10.1 \%$ hypertensive black Bantu Congolese children in this study is intermediate between those from non-Bantu Sudanese and Egyptian children $[5,11]$ and that of $29.4 \%$ black Bantu South African children [6]. These differences are related to standards of developing or emerging economies, overweight/obesity [17-19], and ethnic/genetic factors [3, 22].

Disparities were also found outside of Africa, such as $1.08 \%$ in Argentina [25], 7.4\% in Canada [12], and $19.6 \%$ in Greece [26], highlighting not only the level of development, but also the impact of policies to prevent these countries [4]. Variations in prevalence have been reported within the same country. This is the case of China, where the prevalence of $9.8 \%$ to $20.2 \%$ was observed from different regions [14, 27]. These gaps are certainly explained by differences of development between regions of high growth in this country. On the other hand, in India, the prevalence appears to be more constant, which Genovesi et al. reported as 5.2\% [28], Sharma et al. as 5.9\% [13], and Buch et al. as 6.48\% [29]. Indeed, in this country, although the economic emergence is 
initiated, the divisions are still significant and the social level is still low, with non-westernized eating habits [13].

Unlike pre-HT only overweight and obesity were risk factors of HT in our study. Indeed, it is both classic factors of HT in children in various parts of the world [17-19].

\section{Conclusion}

Both prevalences of pre-HT and HT are recognized as a public health problem in schoolchildren from Brazzaville, Congo. The most important contributing factors for pre-HT and HT are migration, overweight, and obesity. Prevention and control of the consequences of lack of education are needed urgently in Congolese children.

\section{Conflict of Interests}

The authors declare that there is no conflict of interests regarding the publication of this paper.

\section{Acknowledgments}

To carry out the survey, logistical support was obtained from the head of University Hospital of Brazzaville. The completion of the study in Poto-Poto District was facilitated by Ms. Pierrette Opimbat-Mboundza. The authors thank all investigators: Dr. Sah Mbou Bertrand, Dr. Nina Ngoyi Ontsira, Dr. ELION-Ossibi Pierlesky, Dr. Bouhelo-Pam Kevin, Dr. Thogo Lande, Dr. Poaty Pierre, Miss Okiemy Cardinale, Mr. NKOUA Fabrice, Mr. NGOUMA Amour, and Mr. Ngueguie Kessara.

\section{References}

[1] G. Kimbally-Kaky, T. Gombet, J. D. Bolanda et al., "Prevalence of arterial hypertension at Brazzaville," Tropical Cardiology, vol. 32, no. 127, pp. 43-46, 2006.

[2] S. Borici, N. B. Agaoglu, O. A. Baykan, and M. Agirbasli, "Blood pressure and anthropometric measurements in Albanian versus Turkish children and adolescents," Acta Cardiologica, vol. 64, no. 6, pp. 747-754, 2009.

[3] A. Chiolero, G. Paradis, G. Madeleine, J. A. Hanley, F. Paccaud, and P. Bovet, "Discordant secular trends in elevated blood pressure and obesity in children and adolescents in a rapidly developing country," Circulation, vol. 119, no. 4, pp. 558-565, 2009.

[4] Y. Ostchega, M. Carroll, R. J. Prineas, M. A. McDowell, T. Louis, and T. Tilert, "Trends of elevated blood pressure among children and adolescents: data from the National Health and Nutrition Examination Survey 1988-2006," American Journal of Hypertension, vol. 22, no. 1, pp. 59-67, 2009.

[5] Z. Salman, G. D. Kirk, and M. D. Deboer, "High rate of obesityassociated hypertension among primary schoolchildren in Sudan," International Journal of Hypertension, vol. 2011, Article ID 629492, 5 pages, 2011.

[6] C. Kemp, A. E. Pienaar, and A. E. Schutte, "The prevalence of hypertension and the Relationship with body composition in grade 1 learner in the northwest province of South Africa," South African Journal of Sports Medicine, vol. 23, pp. 117-122, 2011.
[7] G. Kimbally-Kaky, T. Gombet, Y. Voumbo et al., "Rheumatic heart disease in school children in Brazzaville," Medecine Tropicale, vol. 68, no. 6, pp. 603-605, 2008.

[8] E. Lurbe, R. Cifkova, J. K. Cruickshank et al., "Management of high blood pressure in children and adolescents: recommendations of the european society of hypertension," Journal of Hypertension, vol. 27, no. 9, pp. 1719-1742, 2009.

[9] M. F. Rolland-Cachera, "Childhood obesity: current definitions and recommendations for their use," International Journal of Pediatric Obesity, vol. 6, no. 5-6, pp. 325-331, 2011.

[10] "The fourth report on the diagnosis, evaluation, and treatment of high blood pressure in children and adolescents: national high blood pressure education program working group on High blood pressure in children and adolescents," Pediatrics, vol. 114, supplement 2, pp. 556-576, 2004.

[11] M. A. Abolfotouh, S. A. Sallam, M. S. Mohammed, A. A. Loutfy, and A. A. Hasab, "Prevalence of elevated blood pressure and association with obesity in egyptian school adolescents," International Journal of Hypertension, vol. 2011, Article ID 952537, 8 pages, 2011.

[12] M. Salvadori, J. M. Sontrop, A. X. Garg et al., "Elevated blood pressure in relation to overweight and obesity among children in a rural canadian community," Pediatrics, vol. 122, no. 4, pp. e821-e827, 2008.

[13] A. Sharma, N. Grover, S. Kaushik, R. Bhardwaj, and N. Sankhyan, "Prevalence of hypertension among schoolchildren in Shimla," Indian Pediatrics, vol. 47, no. 10, pp. 873-876, 2010.

[14] X. Guo, L. Zheng, Y. Li et al., "Gender-specific prevalence and associated risk factors of prehypertension among rural children and adolescents in Northeast China: a cross-sectional study," European Journal of Pediatrics, vol. 172, no. 2, pp. 223-230, 2013.

[15] C. E. C. C. Ejike, C. E. Ugwu, and L. U. S. Ezeanyika, "Variations in the prevalence of point (pre)hypertension in a Nigerian school-going adolescent population living in a semi-urban and an urban area," BMC Pediatrics, vol. 10, article 13, 2010.

[16] C. Agyemang, W. K. Redekop, E. Owusu-Dabo, and M. A. Bruijnzeels, "Blood pressure patterns in rural, semi-urban and urban children in the Ashanti region of Ghana, West Africa," BMC Public Health, vol. 5, article 114, 2005.

[17] G. Paradis, M. Lambert, J. O’Loughlin et al., "Blood pressure and adiposity in children and adolescents," Circulation, vol. 110, no. 13, pp. 1832-1838, 2004.

[18] A. A. Oduwole, T. A. Ladapo, I. B. Fajolu, E. N. Ekure, and O. F. Adeniyi, "Obesity and elevated blood pressure among adolescents in Lagos, Nigeria: a cross-sectional study," BMC Public Health, vol. 12, no. 1, article 616, 2012.

[19] A. K. Saha, N. Sarkar, and T. Chatterjee, "Health consequences of childhood obesity," Indian Journal of Pediatrics, vol. 78, no. 11, pp. 1349-1355, 2011.

[20] A. E. Schutte, J. M. van Rooyen, H. W. Huisman, H. S. Kruger, N. T. Malan, and J. H. de Ridder, "Dietary risk markers that contribute to the aetiology of hypertension in black South African children: the THUSA BANA study," Journal of Human Hypertension, vol. 17, no. 1, pp. 29-35, 2003.

[21] F. J. He, N. M. Marrero, and G. A. MacGregor, "Salt and blood pressure in children and adolescents," Journal of Human Hypertension, vol. 22, no. 1, pp. 4-11, 2008.

[22] L. Ke, K. E. Brock, R. V. Cant, Y. Li, and S. L. Morrell, "The relationship between obesity and blood pressure differs by ethnicity in Sydney school children," American Journal of Hypertension, vol. 22, no. 1, pp. 52-58, 2009. 
[23] J. M. Sorof, D. Lai, J. Turner, T. Poffenbarger, and R. J. Portman, "Overweight, ethnicity, and the prevalence of hypertension in school-aged children," Pediatrics, vol. 113, no. 3, pp. 475-482, 2004.

[24] J. Feber and M. Ahmed, "Hypertension in children: new trends and challenges," Clinical Science, vol. 119, no. 4, pp. 151-161, 2010.

[25] N. Zeberio, A. Malpeli, M. Apezteguia, M. A. Carballo, and H. F. Gonzalez, "Nutritional status of school-aged children its relation to blood pressure," Archivos Argentinos de Pediatria, vol. 111, pp. 92-97, 2013.

[26] A. Kollias, I. Psilopatis, E. Kragiaouri et al., "Adiposity, blood pressure, and carotid intima-media thinckness in Greek adolescents," Obesity, vol. 21, no. 5, pp. 1013-1017, 2013.

[27] Y.-H. Hu, K. H. Reilly, Y.-J. Liang et al., "Increase in body mass index, waist circumference and waist-to-height ratio is associated with high blood pressure in children and adolescents in China," Journal of International Medical Research, vol. 39, no. 1, pp. 23-32, 2011.

[28] S. Genovesi, L. Antolini, M. Gallieni et al., "High prevalence of hypertension in normal and underweight Indian children," Journal of Hypertension, vol. 29, no. 2, pp. 217-221, 2011.

[29] N. Buch, J. Goyal, N. Kumar, I. Parmar, V. Shah, and J. Charan, "Prevalence of hypertension in school going children of Surat city, Western India," Journal of Cardiovascular Disease Research, vol. 2, no. 4, pp. 228-232, 2011. 


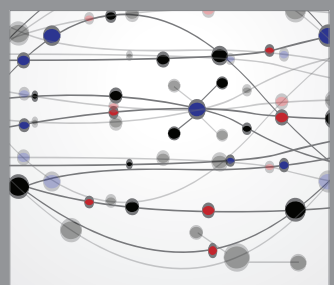

The Scientific World Journal
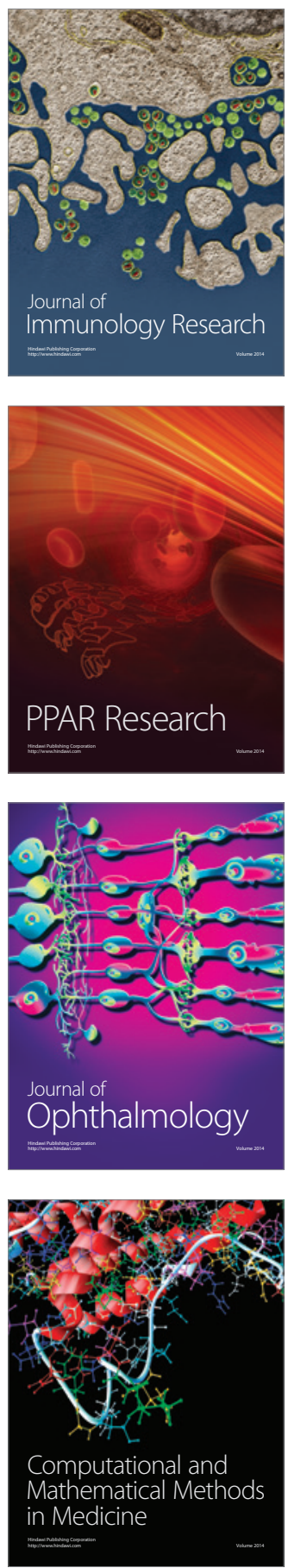

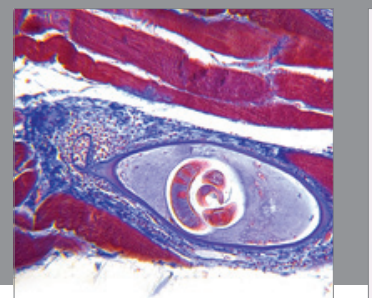

Gastroenterology

Research and Practice
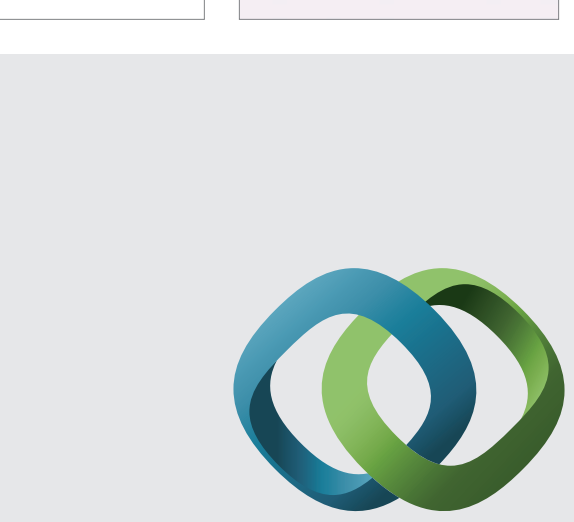

\section{Hindawi}

Submit your manuscripts at

http://www.hindawi.com
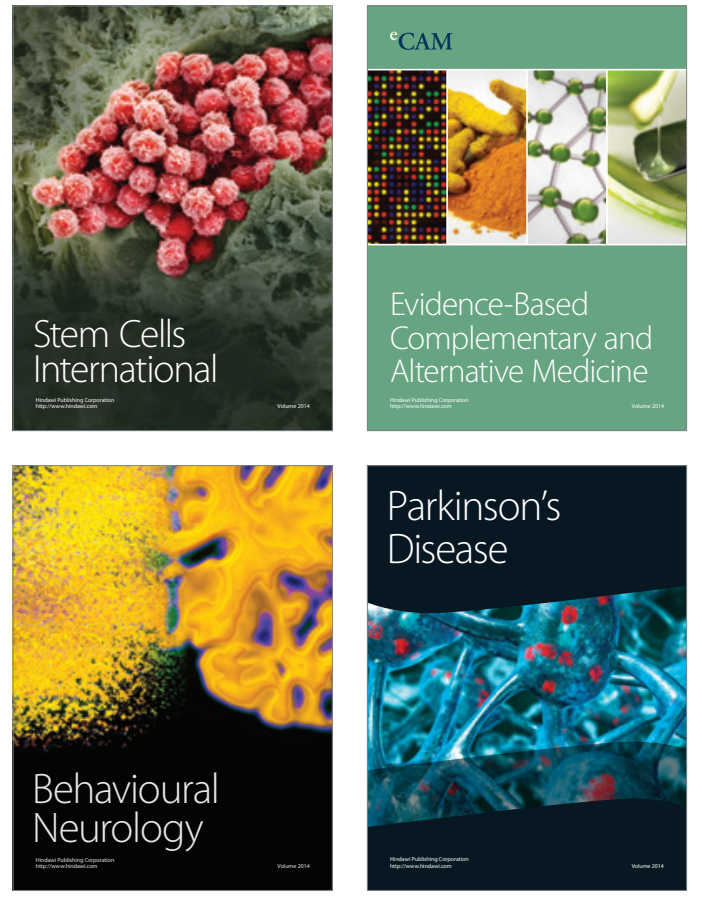
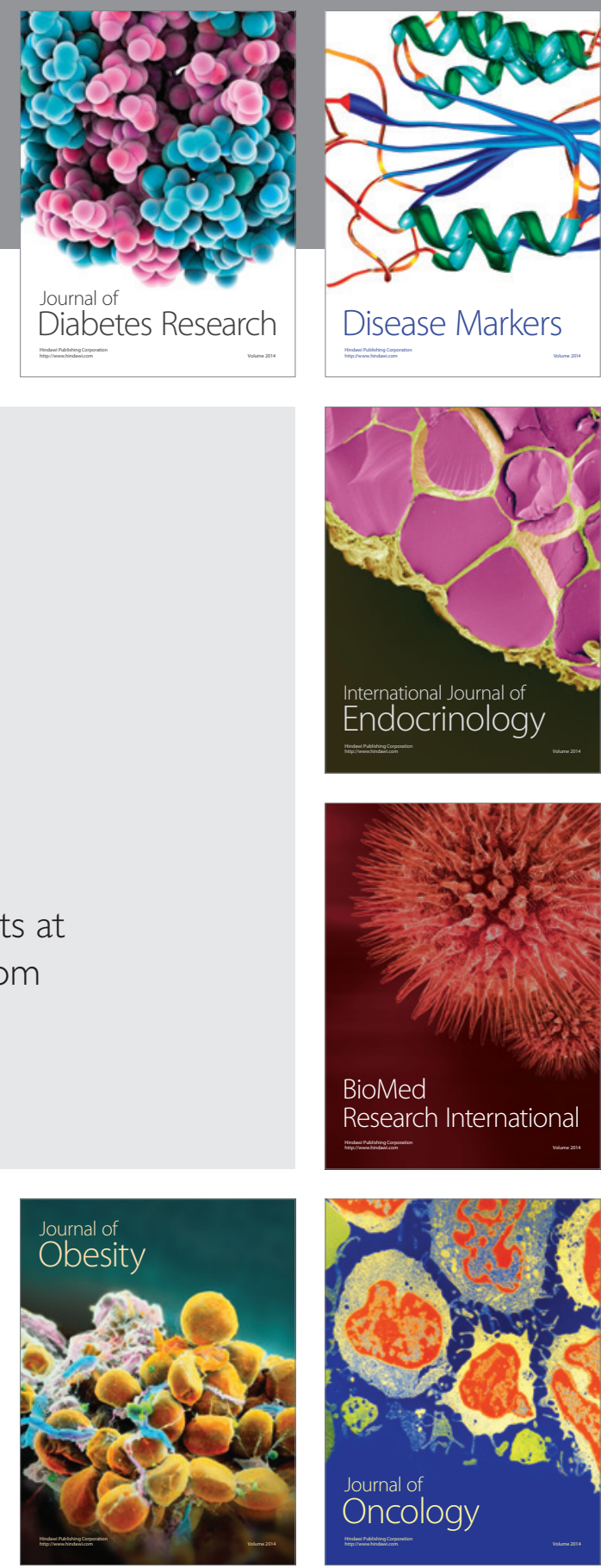

Disease Markers
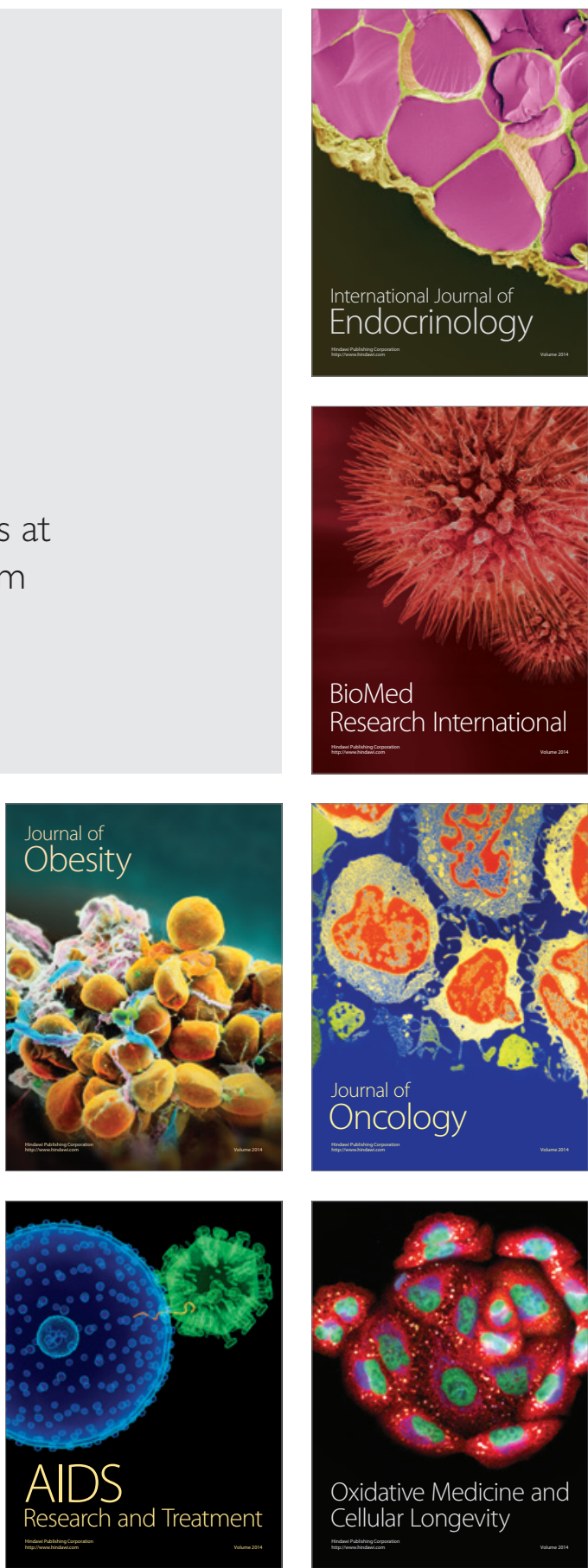